УДК 78.03

\author{
Лу До, \\ соискатель кафедры теории музыки и композиции \\ Одесской национальной музыкальной академии имени А. В. Неждановой \\ odma_n@ukr.net

\section{ЛЕЙТМОТИВИТИЗМ ЦИКЛА «ИНТЕРМЕЦЦО» ОР. 4 РОБЕРТА ШУМАНА}

Цель статьи - проанализировать жанр интермеццо для фортепиано в творчестве Р. Шумана с точки зрения лейтмотивной системы. Методология: в статье применены текстологический, аналитический и компаративный подходы. Научная новизна: в статье рассмотрены черты лейтмотивизма в фортепианных Интермеццо ор. 4 Р. Шумана, показана роль лейтмотивной системы в Интермецио Р. Шумана, выявляются различные сложнейшие взаимосвязи между Интермецио и доказывается их единство, иикличность, сюитность. Выводы: рассмотрев пьесы сюитного цикла «Интермецио» Роберта Шумана, приходим к выводу, что все пьесы данного сюитного иикла находятся в определенном вариантно-вариационном соотношении и взаимосвязаны между собой лейтинтонациями, лейтмотивами, лейтгармонией, лейтритмом, лейттемами, лейтобразами. Таким образом, изучение фортепианного иикла «Интермецио» Роберта Шумана становится актуальной проблемой музыкознания и исполнительства.

Ключевые слова: Роберт Шуман, Интермецио, лейтмотивная система, жанр, вариантно-вариационное соотношение, лейтинтонация, лейтмотив, лейтгармония, лейтритм, лейттема, лейтобраз.

Lu Do, applicant of the department of music theory and composition, Odessa National A. V. Nezhdanova Academy of music

Leitmotivism of the cycle "Intermezzo» op. 4 by Robert Schumann

Article purpose is analyses the Schuman's genre Intermezzo for piano from the point of view of leitmotiv system. Methodology of the article is textual, analytical, and comparative approaches. Scientific novelty: in article lines of a leitmotivizm in piano $R$. Schuman's Intermezzos op. 4 are considered, the role of leitmotiv system is shown in the Intermezzo by $R$. Schuman, various most difficult interrelations between the Intermezzo come to light and their unity, recurrence, a «suitnost» is proved. Conclusions. Having considered plays of a suite cycle of the Intermezzo of Robert Schuman, we have come to a conclusion that all plays of this suite cycle are in a certain alternative and variation ratio and are interconnected among themselves by leit-intonation, keynotes, a leit-harmony, leit-rythm, leit-themes, leit-images. Thus, studying of the piano cycle 
«Intermezzo» of Robert Schuman becomes a current problem of musicology and performance.

Keywords: Robert Schumann, Intermezzo, leitmotiv system, genre, variant-variation correlation, leit-intonation, leitmotiv, leit-harmony, leit-rhythm, leit-theme, leit-image.

Лу До, здобувач кафедри теорії музики та композиції Одеської національної музичної академії імені А. В.Нежданової

Лейтмотивізм цикла «Інтермещо» ор. 4 Роберта Шуманаю

Мета статті - проаналізувати жанр інтермецио для фортепіано в творчості Р. Шумана з точки зору лейтмотивной системи. Методологія: в статті застосовані текстологічний, аналітичний $і$ компаративний підходи. Наукова новизна: у статті розглянуті риси лейтмотівізма у фортепіанних Інтермецо ор. 4 Р. Шумана, показана роль лейтмотивної системи в Інтермецо Р. Шумана, виявляються різні складні взаємозв'язки між Інтермецо і доводиться їх єдність, циклічність, сюїтність. Висновки: розглянувщи п'єси сюїтного циклу «Інтермецо» Роберта Шумана, доходимо висновку, що всі п'єси даного сюїтного ииклу знаходяться в певному варіантно-варіаційному співвідношенні і взаємопов'язані між собою лейтінтонаціями, лейтмотивами, лейтгармонією, лейтритмом, лейттемами, лейтобразами. Таким чином, вивчення фортепіанного ииклу «Інтермецо» Роберта Шумана стає актуальною проблемою музикознавства та виконавства.

Ключові слова: Роберт Шуман, Інтермецо, лейтмотивна система, жанр, варіантно-варіаційне співвідношення, лейтінтонація, лейтмотиви, лейтгармонія, лейтритм, лейттема, лейтобраз.

Актуальность исследования. Интермеццо - оригинальный жанр, возникший достаточно поздно - в 30-е годы XIX века в фортепианной западноевропейской музыке. Его родоначальником стал великий композитор, представитель эпохи Романтизма, творчество которого отмечено многими жанровыми и стилистическими находками и открытиями, - Роберт Шуман. Именно им в 1832 году были созданы произведения нового жанра - Интермеццо для фортепиано (ор. 4), которые очень популярены у пианистов, в том числе у студентов вузов как Украины, так и Китая.

Цикл шести Интермеццо Р. Шумана популярен в курсах музыкальной литературы западноевропейских стран и истории зарубежной музыки; в курсах анализа музыкальных форм и анализа музыкальных произведений; истории фортепианной музыки и истории фортепианного исполнительства. Поэтому актуальность статьи проявляется в необходимости разобраться в лейтмотивных особенностях цикла Р. Шумана «Интермеццо» ор. 4, что, на наш взгляд, 
является очень важным как для исполнителей, так и для преподавателей.

Анализ исследований и публикаций. Наличие литературы по данной теме не значительное, поскольку к особенностям этого жанра музыкознание еще не проявило заинтересованности. Вместе с тем литература о жизни и творчестве Шумана очень велика. Фортепианное творчество Роберта Шумана рассматривается в ряде монографий Д. Житомирского [5], А. Меркулова [15] и др. Д. Житомирский в монографии о Шумане не рассматривает особенности формообразования в «Интермеццо», помещая заметки о данном цикле в раздел «Сюиты, сборники, пьесы», а не в раздел «Вариации и сюиты «сквозного» строения», что косвенно определяет позицию автора [5]. А. Лахути, изучая «сюиты единого строения» композитора, вовсе не включает в этот круг «Интермеццо» Шумана и потому не касается этого произведения [13]. Между тем в Интермеццо содержатся черты, во многом характерные именно для шумановских свободных вариаций и сюит «сквозного» строения, пронизанные лейтмотивизмом. Нами также использована статья Г. Демченко о фортепианной музыке Шумана [4].

Цель статьи - проанализировать жанр Интермеццо для фортепиано в творчестве Р. Шумана с точки зрения лейтмотивной системы.

Объектом статьи являются фортепианные произведения Роберта Шумана в контексте романтических тенденций XIX века, предметом - лейтмотивная система в Интермеццо для фортепиано Р. Шумана.

Научная новизна. В статье рассмотрены черты лейтмотивизма в фортепианных Интермеццо ор. 4 Р. Шумана, показана роль лейтмотивной системы в Интермеццо Р. Шумана, выявляются различные сложнейшие взаимосвязи между Интермеццо и доказывается их единство, цикличность, сюитность.

Изложение основного материала. Интермеццо - самостоятельный жанр в творчестве Роберта Шумана. Шесть пьес под общим названием Интермеццо (ор. 4, 1832 г.) - одно из талантливейших сочинений молодого Шумана.

По сравнению с «Бабочками», завершенными в предшествующем году, тематический материал стал более своеобразным, характерным, ярко образным. Это одно из первых сочинений, где композитор использует композиционную технику, примененную в «Давидсбюндлерах» . 
Если учесть большую самостоятельность пьес Интермеццо, объединяющая функция интонационного лейткомплекса становится особенно существенной. Фактура произведений Шумана индивидуальна. Огромное значение в его творчестве имеет полифоническое мышление. Цикл Интермеццо буквально пронизан полифонической фактурой, имитациями, канонами и т. п.

Шуман считал, что в теории он «школьник», хотя в композиторской практике уже обладал солидным багажом: Вариации на тему Abegg, «Бабочки», Первая тетрадь этюдов по каприсам Н. Паганини, Интермеццо, Экспромт на тему Клары Вик, симфония g-moll, три вариационных цикла - на тему из Аллегретто Седьмой симфонии Л. ван Бетховена, на тему Р. Шуберта и ноктюрна Ф. Шопена. Позже Шуман придирчиво критиковал свои ранние произведения и многие из них «доделывал». Тем не менее «Бабочки», Интермеццо ор. 4, Экспромт ор. 5 - это уже, несомненно, «начало настоящего Шумана, работы блестящего и оригинальнейшего мастера» $[5,138]$. Мы бы сказали точнее: это уже произведения истинного Шумана.

Интермеццо (Intermezzi) Шумана посвящены И. Калливоде чешскому композитору, скрипачу и дирижеру. Состоит фортепианный цикл «Интермеццо» Роберта Шумана из 6 пьес:

1. Allegro quasi maestoso - A-dur;

2. Presto a capriccio - $e$-moll;

3. Allegro marcato - a-moll;

4. Allegro semplice $-C$-dur;

5. Allegro moderato - d-moll;

6. Allegro - h-moll.

В основе всех Интермеццо - быстрый темп (т. е. не используется сюитный принцип медленно-быстро), все пьесы написаны в разных тональностях: A-dur $-e$-moll $-a$-moll $-C$-dur $-\mathbf{d}$-moll $-\mathbf{h}$-moll.

В цикле оказываются два тональных устоя: ля (№ $1,5,6)$ и до мажор (№ 2, 3, 4), с каждым из которых связаны по три пьесы тональностями первой степени родства. Первая тональная тройка (плагальная) объединена основной тональностью A-dur - это начальная (№ 1) и две заключительные (№ 5 и 6) пьесы цикла: A-dur d-moll $-\mathbf{h}$-moll $(\mathbf{T}-\mathbf{s}-\mathbf{I I})$. Вторая тональная группа - срединная (№ 2-4) - связана с низко-терцовой тональностью C-dur и все пьесы (также терцового соотношения) направлены к ней, как к временной тонике и составляют терцовую функцию: e-moll $-\mathbf{a}-\mathbf{m o l l}-$ C-dur (III - VI - T). 
Наблюдается еще одна тональная тенденция в пьесах цикла - разделение на две части по три Интермеццо: мажор - минор - минор и мажор - минор - минор; причем каждая часть начинается с тонального устоя, за которым следуют тональности иного уровня.

Bce пьесы цикла исполняются быстро (Allegro) и отличаются лишь неповторяющимися уточнениями особенностей этого темпа: quasi maestoso (как бы торжественно), a capriccio, marcato, semplice, moderato (только последняя не очень дополняет содержательности к темпу - не торопливо). Как видим, ремарки встречаются трех видов: чисто темповые (moderato), характерные (quasi maestoso, marcato), характерно-жанровые (a capriccio, как бы дополняя Интермеццо № 2 жанром каприччио).

Как и во всех ранних циклах, темы Интермеццо лаконичны и их достаточно много. Эти темы часто сопоставляются между собой, а не внутренне развиваются, хотя и этот тип развертывания музыкальной мысли также встречается.

Важны также черты вариационности, проявившиеся в разных фортепианных пьесах Шумана («Интермеццо», «Крейслериана», «Юмореска», «Карнавал»), составляющих сюитные циклы. Самостоятельность тематизма пьес «Интермеццо», объединяющая функция интонационного лейткомплекса особенно существенны. Заметны и другие черты, свойственные стилю фортепианных циклов Шумана, - сюжетная программа, своеобразное обрамление - родственность главных тем Интермеццо № 2 и № 6. Они близки пассажным движением, лирическим волнением и смятенностью, ассоциирующимися (особенно в последним) со Скерцо b-moll Ф. Шопена, а также стремлением к следованию частей без перерыва.

Ф. Мэй отмечала в «Интермеццо» «недостаток связей в структуре и некоторую расплывчатость мелодизма», хотя и указывала, что «произведение находится на более высоком уровне, чем «Бабочки», содержит типично шумановские образы, например, характерный для Шумана «накаленный порыв» знаменует использование нового метода выражения и предрекает хорошие творческие перспективы» [31, 84]. Немецкий музыковед Р. Хоэнемзер называет «Интермеццо» сборником и указывает: «Возможно, что самым проблематичным в том, что касается целостности, является сборник «Интермеццо», ор. 4» [29, 39]. Но пьесы Интермеццо необычайно едины и буквально спаяны воедино.

Интермеццо Шумана вполне можно назвать сюитным циклом. В нем имеется своеобразная интонационная основа, которая, экспо- 
нируясь в начале первого номера и повторяясь дважды в практически неизменном и дважды в измененном виде в этом Интермеццо, появляется также в различных вариантах во всех остальных пьесах цикла, объединяя их воедино.

Интонационная основа цикла (первые три такта) представляет собой две нисходящие секундовые интонации (сравним с двумя начальными интонациями «Крейслерианы»), направленные от IV к III ступени лада - в первой ячейке и от I к VII - во второй. В басу им противостоит движение восходящих секунд. Образуется сцепление двух квинтсекстаккордов с разрешением (D-T; DD-D). C гармонией связано и голосоведение: нисходящее движение параллельными терциями верхних голосов и противоположное движение басов. Отмеченные особенности интонационной основы, а также гармонического содержания сохраняются при новых появлениях исходной лейтосновы цикла.

Интонационная основа фортепианного цикла Шумана «Интермеццо» - лейткомплекс - это повторяющиеся в различных ритмических вариантах последовательности ступени IV - III - I - VII (в начале), IV - III - IV - III - I - VII (реприза); IV - III - I - IV III - I (из № 2); III - VII - V9 - I (из № 3); IV - III - IV - III - IV (из № 5); I - VII (из № 6 - завершение первого периода; конец номера) и др.

Часто проведения первой интонационной ячейки следуют попарно (по типу двух интонаций в начале) в разных тональностях. В № 4 ритмические опоры мотивов и ямбические затакты к ним строятся на тех же ступенях лада, что и в исходном образовании (I - VII IV - III). Отмеченные ступени, особенно последовательность IVIII, заметны и в других лирических темах цикла: так в № 5 (тт. 28-32: IV - III), в середине № 2 (IV - III; IV - III; IV - III), в эпизодах Des-dur из № 3. Так, эпизод Des-dur в № 3, написанный в одноименном по отношению к общему вступлению a-moll, основывается на неполном первом звене вступления (остается лишь III ступень) и практически неизменном втором; можно также представить первые 32-е как обращение исходного мотива - это вполне в духе контрапунктических увлечений Шумана того периода (как известно, он усиленно штудирует учебники Марпурга, изучает фуги И. С. Баха). К тому же этот прием вносит скерцозный оттенок (вспомним аналогичное по смыслу обращение интервала интонации в № 12 «Давидсбюндлеров» Шумана). 
Имеются и более свободные варианты использования лейткомплекса. Показательно, что в заключительных тактах всего цикла он отчетливо слышен (см. конец № 6). В двух последних аккордах здесь можно услышать своеобразную антитезу началу - первому звену исходного образования: мелодия дана в обращении, ритмическом увеличении и в другой гармонизации при сохранении звуко-высотного уровня и плотной фактуры сопровождения. К такому восприятию подготавливают парные аккордовые звенья, которые сконцентрировались в окончаниях разделов последнего Интермеццо.

Композиционное ядро «Интермеццо» в меньшей степени, чем в «Давидсбюндлерах», растворено в тематизме пьес. Полнее сохраняя первоначальный облик, это ядро, достаточно самостоятельное и автономное, появляется как лейтмотив, «как своего рода навязчивая идея, не оставляющая «героя» произведения на всем протяжении цикла» [5, 43]. Чаще всего данный лейтмотив (элемент темы) возникает в моменты драматического напряжения, завершая предкульминационные нарастания. Такая выразительная функция лейтосновы Первого интермеццо определена уже в начале произведения.

Возможно, к Интермеццо Р. Шумана наиболее подходят слова Г. Головинского: «Метод Шумана... точнее определить как «доращивание» исходной лейтинтонации до темы, каждый раз иной, но не как вариации на тему (выделено нами. - Л. Д.)» $[3,50]$. Впрочем, чаще всего эти принципы у Шумана неразрывны и трудно отделимы друг от друга.

Определенную роль в скреплении пьес цикла «Интермеццо» выполняет интонация $\mathbf{V}-\mathbf{V I}-\mathbf{V}$, появившаяся уже в начале основного раздела № 1 (скачок на нону, с секундовым, ритмически острым, заполнением). Это свободный вариант основного лейткомплекса: главенствует та же интонация d-cis, что и в первой ячейке «мотто»; чуть позже в гаммообразном движении проходят и звуки a-gis второй ячейки вступления; от первоначального импульса заимствуется и пунктирный ритм. И все же данная разновидность тематического ядра достаточно своеобразна и самостоятельна - прежде всего благодаря появлению более широкой мелодической линии и изменению ладового освещения: fis-moll вместо A-duг.

Этот вариант элемента темы, интенсивно экспонирующийся и разрабатывающийся (примечательно, например, его появление в D-duг) и нередко появляющийся в последних номерах цикла, выполняет, таким образом, роль еще одного объединяющего стержня композиции. 
Особенно заметно опевание в начале последнего Интермеццо. Обратим внимание на авторские знаки акцента и «sf», подчеркивающие звуки лейтинтонации. Она также часто звучит, начинаясь с VI ступени. Такой несколько усеченный вариант можно услышать и в начале № 5.

Вероятно, творческим импульсом к созданию этих произведений были какие-то общие и очень близкие внутренние побудительные мотивы, что в итоге и обусловило их родство [5, 45]. Вспомним о возвышенных мечтах, владеющих Шуманом еще до написания цикла «Интермеццо» (Обратим внимание на одну из дневниковых записей композитора 1831 года: «Я хочу измениться, я клянусь тебе в этом дай мне только одного человека, одного единственного, которому я могу отдать сердце - любимую, любимую, дай мне женское сердце женское сердце!» [цит. по: 15,45$])$. Напомним также, что сочинение было первоначально посвящено тогда еще совсем юной Кларе Вик... $[5,351]$. Отметим, что в цикле «Интермеццо» именно в начальной интонации VI-V концентрируется лирическая экспрессия пьесы.

В больших шумановских циклах невариационного типа обнаруживаются, на первый взгляд, неожиданные, но не случайные, связи между разными, иногда достаточно отдаленными друг от друга, пьесами.

Так уже Интермеццо № 1 содержит все компоненты, объединяющие пьесы сюитного и вариантно-вариационного цикла. Каждая часть Интермеццо отмечена собственным самостоятельным вступлением, выполняющим в дальнейшем важнейшую функцию в развитии драматургии произведения: лейтмотива, а также предвосхищения интонационного, ритмического, тонального, фактурного содержания пьесы и всего цикла. В среднем разделе Alternativo - собственное вступление, в котором намечается лейтритм (вальса) и лейтинтонации (хроматизмы, кварту и квинту).

В других Интермеццо вступления также будут выполнять важную роль для формирования тематизма, фактуры, содержательной драматургии произведения. Во Втором Интермеццо вступление выполняет функцию тональной опоры; в Третьем - гармонической основы (Д7, 6/5) - 2 такта; на них будет основываться срединный эпизод. В маленьком Интермеццо № 4 - иатериал одного такта вступления пронизывает всю пьесу. В Интермеццо № 5 и № 6 вступления отсутствуют.

Обратимся к принципам исполнения «Интермеццо», которые находятся в зависимости от лейтмотивизма, интонационных повторов. 
Исполнитель, стремящийся к целостной интерпретации всего цикла, должен выявить интонационные связи-арки. Шуман несколько облегчает эту задачу исполнителю при помощи различных обозначений короткие лиги, sf, знаки резкого акцента и другие - он тщательно выделяет начало лейткомплекса (что наглядно видно из всего музыкального материала произведений). Более того, иногда интонационное зерно цикла помещается в такие условия (например, на гребень кульминационной динамической волны), что не подчеркнуть его просто невозможно.

И все же исполнителю-интерпретатору остается еще немало аналитической работы, ибо ткань сочинения густа, многозвучна, а проявления лейтосновы не всегда элементарны. Например, в т. 24-27 Интермеццо № 1 вариант тематического элемента (вступления, которое часто недооценивается исполнителями в данной пьесе) обычно не дослушивается и «тонет» в diminuendo. Хотя Шуман предписывает резкие акценты и сгеsceпdo, прерывающиеся внезапным piano. В № 2 (в тт. 142 и 144) интонационный комплекс дважды неожиданно (sf) обнаруживает себя в тихом и прозрачном (pp, leggiero) движении восьмых. При исполнении звучание этих двух разных функциональных элементов ткани не должно быть одинаковым по силе и сливаться в однородный стремительный поток. Так, в № 5 (тт. 37-44 и 174-180), необходимо прослушать интонации элемента, тонко вплетенные в музыкальную ткань.

Но если исполнитель не осознает лейтинтонационности цикла, это отражается на его видении целого. В таком случае пьесы цикла излишне отчленяются одна от другой, игнорируются шумановские указания attacca при переходах от одного Интермеццо к другому, нити, связывающие части иежду собой рвутся.

С точки зрения композиционного строения цикла «Интермеццо», исполнение одной или нескольких пьес считаем неправомерным также, как и исполнение отдельных номеров из «Карнавала», «Давидсбюндлеров» и «Крейслерианы» Шумана.

Обратим внимание, что часто оригинальное название шумановского цикла - «Интермеццо» - не точно переводится как «Шесть интермеццо», что создает иллюзию существования шести отдельных пьес по типу «Интермеццо» И. Брамса $[15,43])$. На самом деле «Интермеццо» Р. Шумана - это единый сюитный цикл.

Рассмотрев пьесы сюитного цикла «Интермеццо» Роберта Шумана, мы пришли к выводу, что все они находятся в определенном 


\section{вариантно-вариационном соотношении и взаимосвязаны между собой} лейтинтонациями, лейтмотивами, лейтгармонией, лейтритмом, лейттемами, лейтобразами.

Таким образом, изучение фортепианного цикла «Интермеццо» Роберта Шумана становится актуальной проблемой музыкознания и исполнительства.

\section{СПИСОК ЛИТЕРАТУРЫ}

1. Головинский Г. Роберт Шуман и русская музыка XIX века // Советская музыка. 1990. № 3. С. 46-54.

2. Демченко Г. Ю. Принципы циклизации миниатюр в фортепианных произведениях Шумана // Роберт Шуман и перекрестье путей музыки и литературы. Сборник научных трудов / Сост. Г. И. Гамбург. Харьков : «РА» «Каравелла», 1997. С. $89-100$.

3. Житомирский Д. В. Роберт Шуман. Очерки жизни и творчества / Д. В. Житомирский. - М. : Музыка, 1964. 880 с.

4. Лахути А. Сюитные циклы Шумана // Труды кафедры теории музыки Московской государственной консерватории. М., 1960. Вып. 1. С. 280-337.

5. Меркулов А. М. Фортепианные сюитные циклы Шумана. Вопросы целостности композиции и интерпретации. М. : Музыка, 1991. 95 с.

6. Шаповалова О. Музыкальный энциклопедический словарь. М. : ООО «РИПОЛ Классик», 2003. 697 с.

7. Шуман Р. Письма (1817-1840) / Пер. с нем. А. А. Штейнберг. Ред. перевода и перевод части писем Н. А. Темчиной. Сост., вст. Статья, комм. Д. В. Житомирский. М. : Музыка, 1970. Т. 1.719.

\section{REFERENCES}

1. Golovinskiy, G. (1990). Robert Schumann and Russian Music of the 19th Century. Soviet music (Vol. 3), (pp. 46-54). Moscow [in Russian].

2. Demchenko, G. (1997). Principles of cyclization of miniatures in the piano works of Schumann. G. I. Gamburg (Eds.). Robert Schumann and the crossroads of the ways of music and literature. Collection of scientific works, (pp. 89-100), Harkov : «RA» - «Karavella» [in Russian].

3. Zhitomirskiy, D. (1964). Robert Schumann. Essays on life and creativity. Moscow: Muzyika [in Russian].

4. Lakhuti, A. (1960). Suite cycles by Schumann. Works of Department of Music Theory of the Moscow State Conservatory (Vol. No. 1), (pp.280-337). Moscow [in Russian]..

5. Merkulov, A. (1991). Suite cycles by Schumann. Questions the integrity of the composition and interpretation. Moscow.: Muzyika, [in Russian].

6. Shapovalova, O. (2003). The musical encyclopedic dictionary Moscow: OOO «RIPOL Klassik» [in Russian]. 
7. Shuman, R. (1970). Letters (1817-1840) Translated from German by A. A. Steinberg. Editor by translation and translation of a part of letters by N. A. Temcina. Comp., introductory Article, comments by D. V. Zhitomirsky (Vol. 1). Moscow.: Muzyika [in Russian].

Стаття надійила до редакції 22.06.2016

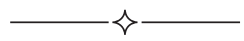

УДК 781.65

\section{Ли Фанюань,}

соискатель кафедры теории музыки и композиции

Одесской национальной музыкальной академии им. А. В. Неждановой odma_n@ukr.net

\section{ОБРАЗЫ «БОЖЕСТВЕННОЙ КОМЕДИИ» ДАНТЕ В ИСТОРИКО-КУЛЬТУРНОМ КОНТЕКСТЕ}

Целью статьи является рассмотрение избранных произведений искусства, связанныхс творческим воспроизведением образов «Божественной комедии» А. Данте. Методология работы состоит в использовании аналитического, фактологического и исторического методов исследования. Указанный методологический подход позволил выявить имена целого ряда создателей, обратившихся в своем творчестве к сюжетам и образам «Божественной комедии» Данте. Науиная новизна. Актуализируется проблема отражения «Божественной комедии» Алигьери Данте в различных видах искусств: к произведению Данте обращались поэты и писатели, скульпторы и художники, а также композиторы. Выводы. Поэты и писатели (О. Шпенглер, О. Мандельштам и др.), скульпторы и художники (Микеланджело, Г. Доре, С. Боттичелли, С. Дали, О. Роден и др.) обычно старались целостно рассматривать произведение Данте. Композиторы - среди них Ф. Лист, П. Чайковский, С. Рахманинов и другие - чаще всего воспроизводили содержание одного и того же фрагмента. Речь идет об интерпретации пятой песни «Ада», когда Данте, сопровождаемый тенью Вергилия, спускается во второй круг Ада.

Ключевые слова: Данте, "Божественная комедия», виды искусства, творческое восприятие, воплощение в поэзии, в литературе, в скульптуре, в живописи, в музыке. 